\title{
A numerical investigation on vibration analysis of fiber reinforced and truncated conical hollow shells with different fiber orientations

\author{
Mehmet BULUT ${ }^{1}$
}

\begin{abstract}
Truncated conical shells have been extensively used in a wide range of engineering applications due to their special geometric shapes, and their vibration properties have been interested by many researchers in recent years. In this study, vibration analysis of truncated conical hollow shells constructed from the fiber reinforced carbon/epoxy composites was investigated for different fiber orientation angles $\left(\left[0^{\circ} / 90^{\circ}\right],\left[15^{\circ} /-75^{\circ}\right],\left[30^{\circ} /-60^{\circ}\right]\right.$, and $\left[45^{\circ} / 45^{\circ}\right]$ ). Finite element analysis (FEA) was performed by using ABAQUS software for prediction of natural frequencies and mode shapes within the extended frequency range. Natural frequency values were determined for constant semi-vertex angle of the conical structure $\left(45^{\circ}\right)$, and boundary conditions of clamped-clamped (C-C), simply supported-simply supported (S-S) and clamped-free (C-F). It is concluded that natural frequency has been significantly affected by boundary conditions while it has been little effected by fiber orientation angle those
\end{abstract} effecting on mode shapes associated with natural frequencies.
}

Keywords: Conical hollow shells, FEA, carbon fiber, fiber orientation angle, natural frequency

Mehmet BULUT (0000-0002-0705-6555), Hakkari Üniversitesi, Mühendislik Fakültesi, Makina Mühendisliği Bölümü, Hakkari, Türkiye Sorumlu yazar/Corresponding Author: Mehmet BULUT, mehmetbulut@hakkari.edu.tr 


\section{INTRODUCTION}

Fiber reinforced composites are extensively used in various engineering applications such as aircrafts, automobiles and marine ships because of their high strength and stiffness to weight ratio compared with other materials. The increasing usage of composite shells has initiated high interest in developing various mathematical models and computational methods to analyze their dynamic characteristics (Xiang et al., 2014), providing high mechanical and dynamic properties such as higher specific stiffness, better damping and shock absorbing, and carrying applied loads effectively because of their curvature (Viswanathan et al., 2015). Composite shell structures can be utilized in weight sensitive applications such as space vehicles and civil roof structures (FengMing et al., 2009). Hence, knowledge of the dynamic properties of truncated conical shells constructed from high performance of fibers should be investigated for controlling dynamic stability of the structural design (Lam et al., 1999). Some researchers (Chang et.al, 1978; Goldberg et.al,1960; Khatri et.al, 1995; Liew et.al, 2005; Goldberg et.al,1992) have been reported on vibration properties of conical shells, while others investigated the vibration characteristics of the conical composite materials dealing with the variety of theoretical methods such as element-free kp-Ritz (Liew et al., 2005), Galerkin method (Lam et al., 1999; Li et al., 2000), Liapunov-Bellman theory (Fares et al., 2004), shear deformation theory based on the discrete singular convolution (Civalek Ö., 2013) and GDQ technique with trigonometric expansion (Akbari et al., 2014). Irie et al. (1984) and Irie et al. (1982) studied numerically the natural frequency and mode shapes of the conical shells for different shell thicknesses and boundary conditions by the application of elements of the transfer matrix. Guoyong et al. (2014) investigated the vibration analysis of truncated conical shells with general elastic boundary conditions by using modified Fourier series, and it is also reported the comprehensive studies the effects of elastic restraint parameters, semivertex angle and the ratio of length to radius. On other hand, dynamic moving load and moving mass problems in the truncated conical shells are essential for engineering problems to predict their vibration problems (Malekzadeh P. and Daraie M., 2014). Hu and Chen (2015) studied free vibration analysis of laminated truncated conical shells subjected to axial compressive forces by using Abaqus FEA. The parameters of the boundary conditions, length of the shell, radius ratio of the shell, and the compressive load on the maximum natural frequency of first mode associated with optimal fiber orientation angle with their mode shapes were studied. Zhaoye et al. (2017) free vibration analysis of cylindrical shells with arbitrary boundary conditions, and it was reported that stiffness in the longitudinal direction has most significant effect on the natural frequencies of the shells.

To the best of the authors' knowledge considering the literature review, it is concluded that conical shell structures made of fiber reinforced composites dealing with effects of fiber orientation angles associated with natural frequency analysis with mode shapes have not been investigated adequately, and this should be studied for safety conical systems. In this study, the effects of fiber orientation angle on natural frequency and mode shapes of truncated shaped fiber reinforced carbon/epoxy composite conical hollow shells were investigated for different end conditions by using FEA by Abaqus software.

\section{MATERIALS AND METHODS}

For the vibration analysis of conical shells, a three dimensional shell analysis has been modelled, and three boundary conditions (C-C-, S-S and C-F) were applied to the edge line of the shells. Material type of shell structures was chosen as fiber reinforced carbon/epoxy composite, and its mechanical properties were evaluated experimentally as given in Table 1 . Conical shell structures were constructed as 48 layers with symmetric configurations. Four different fiber orientation angles with stacking sequences of $\left[(0 / 90)_{24}\right]_{S},\left[(-30 / 60)_{24}\right]_{S},[(-$ $\left.45 / 45)_{24}\right]_{S}$ and $\left[(-75 / 15)_{24}\right]_{S}$ were used for evaluation of mode shapes and vibration frequencies.

Table 1. Mechanical properties of carbon/epoxy composite laminates (Erkliğ et al., 2014)

\begin{tabular}{llllll}
\hline Fiber type & $\mathrm{E}_{1}=\mathrm{E}_{2}(\mathrm{GPa})$ & $\mathrm{E}_{3}=0.6 \mathrm{E}_{1}(\mathrm{GPa})$ & $\mathrm{G}_{12}=\mathrm{G}_{13}=\mathrm{G}_{23}(\mathrm{MPa})$ & $v_{12}$ & $v_{13}=v_{23}=0.6 v_{12}$ \\
\hline Carbon/Epoxy & 49.650 & 29.790 & 5000 & 0.100 & 0.060 \\
\hline
\end{tabular}



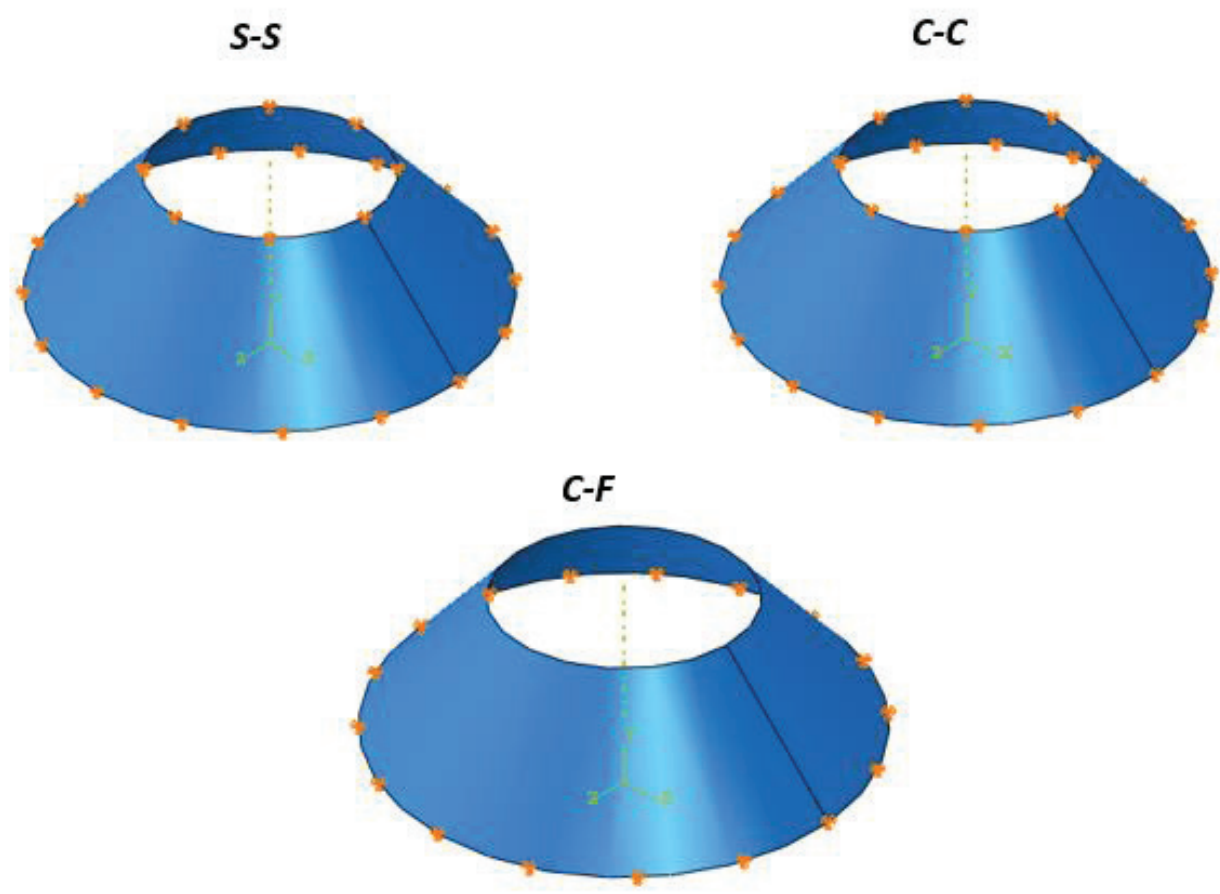

Figure 1. Boundary conditions of the conical shell

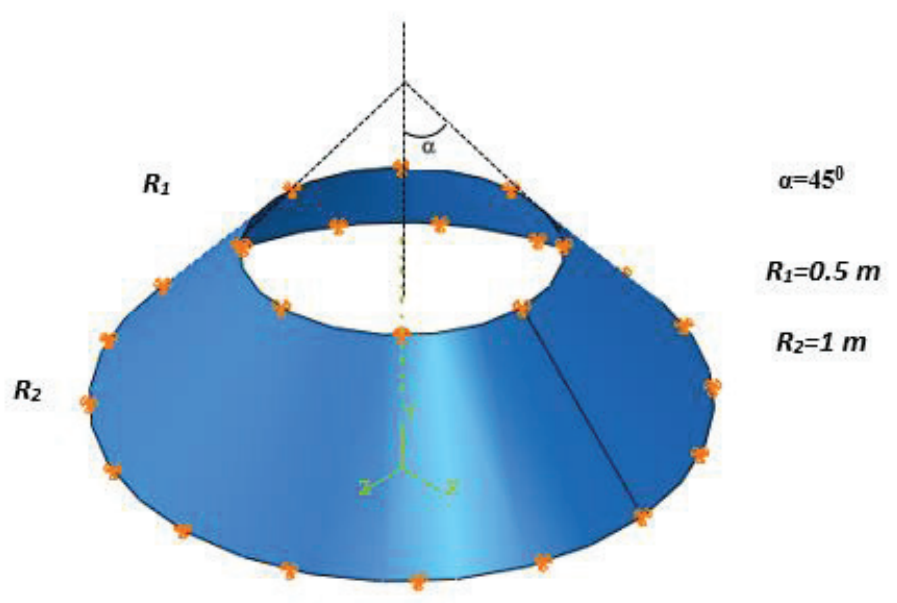

Figure 2. Geometric sizes of the conical shell

\section{NUMERICAL STUDIES}

It is attempted in numerical studies that frequency analysis with Abaqus procedures was used to calculate the natural frequencies and the corresponding mode shapes of the conical shell system. Abaqus 6.11 software has been used for vibration analyses in the current study. While solving the natural frequencies of the system, following eigenvalue equation (Equation 1) was performed to extract natural frequencies (Abaqus User's Manuel, 2011)

$$
\left(-\omega^{2} M^{M N}+K^{M N}\right) \phi^{N}=0
$$


where, $M^{M N}$ is the mass matrix (which is symmetric and positive definite), $K^{M N}$ is the stiffness matrix (which includes initial stiffness effects if the base state included the effects of nonlinear geometry), and $\phi^{N}$ is the eigenvector (the mode of vibration); and $M$ and $N$ are degrees of freedom.

In Abaqus/Standard, Linear perturbation analysis was used for extraction of natural frequencies. Method of Lanczos was used for extraction of eigenvalues. Number of nodes and elements used in the numerical analyses were 1410 and 1316, respectively. Element type of S4R was used for modelling of conical shell structure. S4R is a robust, general-purpose element that is suitable for a wide range of applications, and converges to shear flexible theory for thick shells and classical theory for thin shells.

Five first modes were extracted for different modes and boundary conditions. Figure 2 illustrates the 3D numerical model constructed in Abaqus software.

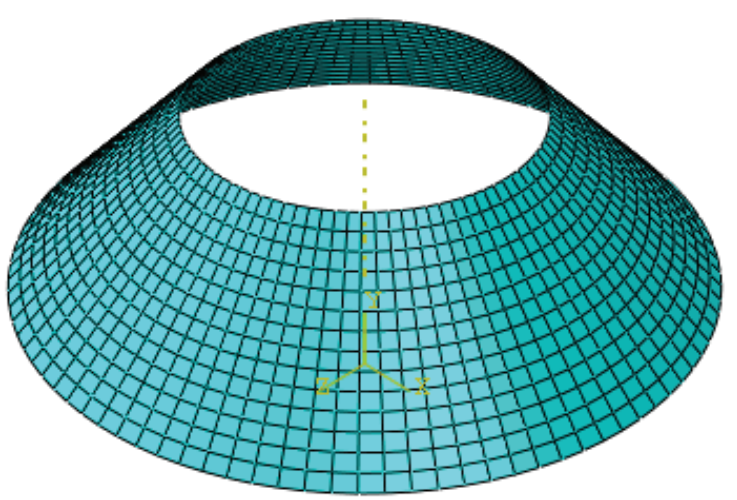

Figure 3. 3-D numerical modelling of conical shell for vibration analysis

\section{RESULTS AND DISCUSSION}

\section{C-F Boundary condition}

Table 2 shows the results of vibration mode frequencies for modelled conical shell structures at boundary condition of C-F, and their variations by means of fiber orientation angle was illustrated in Figure 4. It is concluded that frequency values increases with respect to vibration modes indicating a $12 \%$ improvement, while a little variation has been observed as increasing fiber angle resulting in $0.04 \%$ enhancement at fiber angle of [-75/15], and $0.21 \%$ decreasing at fiber angle of [-45/45]. It is also clear from Figure 4 that optimum frequencies were recorded as Mode 1 and mode 4 at stacking sequence of [-75/15], mode 2 and mode 5 at stacking sequence of [-75/15], and mode 3 at stacking sequence of [0/90]. When increasing mode number from 1 to 5 , maximum enhancement in natural frequency was found $22.28 \mathrm{~Hz}$ at fiber angle of [-45/45]. This small changes of natural frequencies with respect to fiber orientation angle was attributed the size of the conical shell, implying that long size of the conical shell results in higher deviation of natural frequency changes with respect to fiber orientation angles ( $\mathrm{Hu}$ and Chen, 2015; Viswanathan et al. 2015) 
Table 2. Results for C-F boundary condition

\begin{tabular}{ccccc}
\hline \multicolumn{5}{c}{ Fiber angle } \\
\hline Mode & {$[0 / 90]$} & {$[-30 / 60]$} & {$[-45 / 45]$} & {$[-75 / 15]$} \\
\hline $\mathbf{1}$ & 175.1746 & 175.0259 & 174.7927 & 175.2485 \\
\hline $\mathbf{2}$ & 180.5715 & 180.963 & 181.3398 & 180.5434 \\
\hline $\mathbf{3}$ & 191.0892 & 190.4207 & 190.2705 & 190.7412 \\
\hline $\mathbf{4}$ & 192.4645 & 192.6964 & 192.4525 & 192.8983 \\
\hline $\mathbf{5}$ & 196.2973 & 196.6167 & 197.0799 & 196.1098 \\
\hline
\end{tabular}
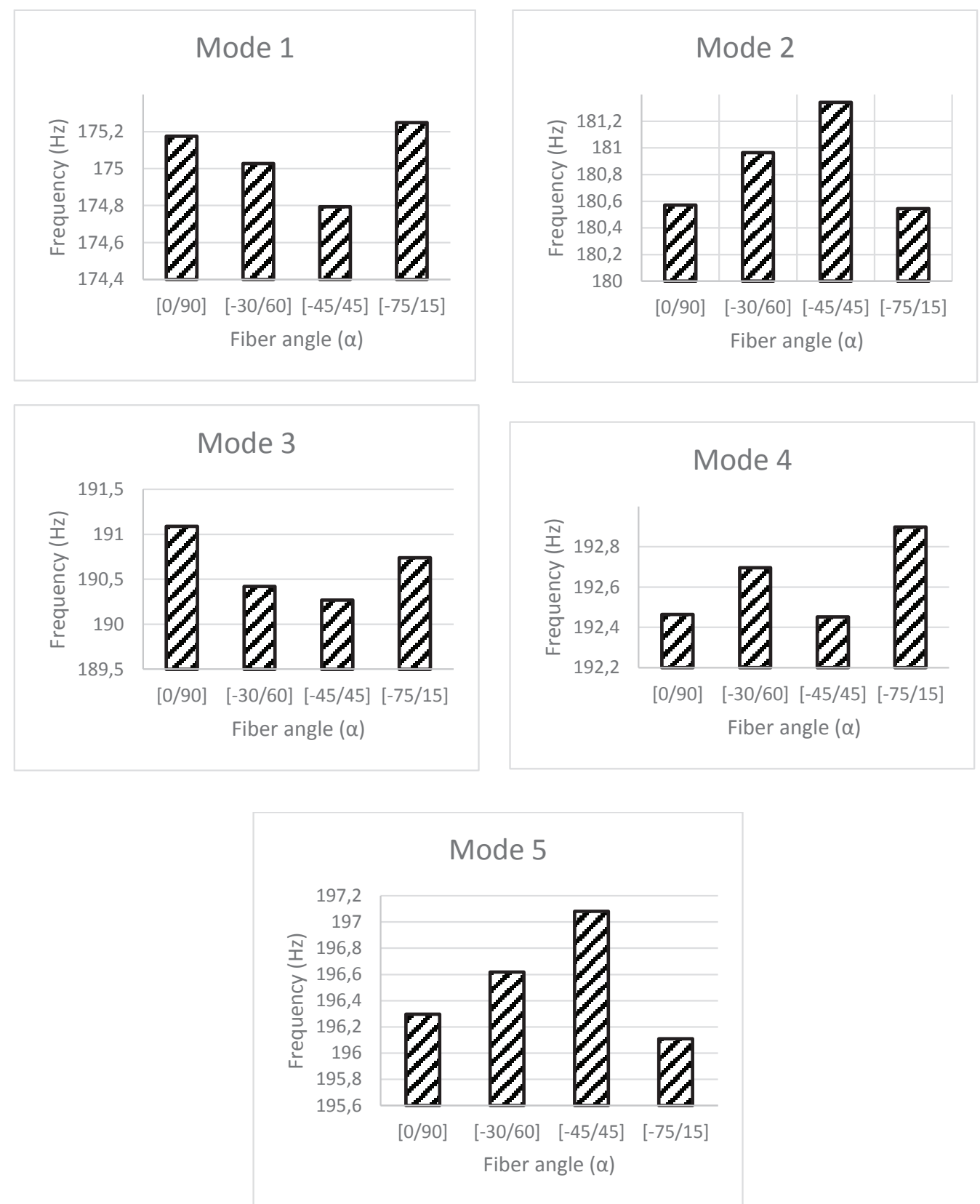

Figure 4. Natural frequency variations of the conical shell structure at different fiber orientation angles and C-F boundary condition 
Table 3 illustrates the mode shapes associated with natural frequencies of conical shell at C-F boundary condition. It is concluded from Table 3 that location and magnitude of maximum deformation have been changed according to mode number and fiber orientation angle significantly affect the safety and stability of the conical system (Dey and Karmakar, 2012)

Table 3. Mode shapes for C-F boundary condition

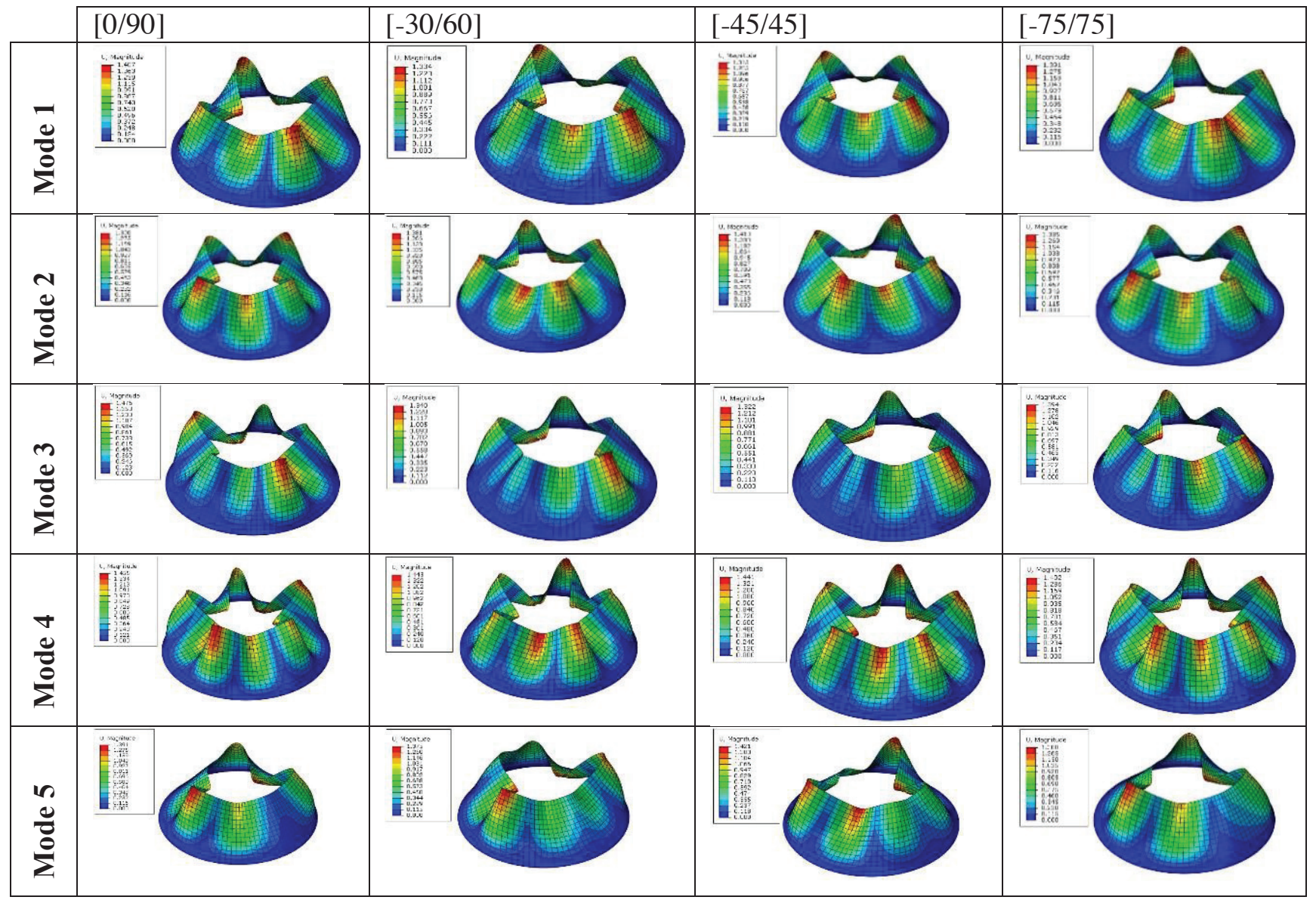

\section{C-C Boundary condition}

Table 2 shows the results of natural frequencies of the conical shell structure under the $\mathrm{C}-\mathrm{C}$ boundary condition. For a better comparison, the influence of fiber orientation on vibration mode frequencies was also presented in Figure 5. It is remarked that vibration frequencies has been increased significantly by chancing boundary condition from $\mathrm{C}-\mathrm{F}$ to $\mathrm{C}-\mathrm{C}$, implying that boundary condition of $\mathrm{C}-\mathrm{C}$ provides more stable and effective to resist vibration based failures compared with boundary condition of C-F. Changing the boundary condition from $\mathrm{C}-\mathrm{F}$ to $\mathrm{C}-\mathrm{C}$ results in a variation of the optimum working frequency value. It is also clear from Figure 5 that, conical structure exhibits an optimum working frequency at mode numbers of 1, 2, 3, and 4. However, mode 5 reveals the optimum frequency even though its frequency is very close to mode 1 .

Table 5 illustrates the mode shapes associated with natural frequencies of conical shell at C-C boundary condition. It is noted from Table 5 that fiber orientations and boundary condition results in a significant effect on modal shapes and deformations, leading to a significant effects on the safety and stability of the system. Several researchers (Viswanathan et al., 2015; Xiang et al., 2014) have reported on influence of edge conditions and geometric properties on vibration properties of conical composite shells, declaring that increasing edge constraint results in increasing of natural frequency. 
Table 4. Results for C-C boundary condition

\begin{tabular}{ccccc}
\hline \multicolumn{5}{c}{ Fiber angle } \\
\hline Mode & {$[0 / 90]$} & {$[-30 / 60]$} & {$[-45 / 45]$} & {$[-75 / 15]$} \\
\hline $\mathbf{1}$ & 270.9062 & 273.5388 & 275.3314 & 271.3456 \\
\hline $\mathbf{2}$ & 272.5149 & 276.0063 & 276.705 & 273.8021 \\
\hline $\mathbf{3}$ & 272.7148 & 276.3525 & 277.4362 & 274.239 \\
\hline $\mathbf{4}$ & 274.5666 & 277.3479 & 278.0999 & 275.3881 \\
\hline $\mathbf{5}$ & 291.6569 & 291.1653 & 290.4843 & 291.9715 \\
\hline
\end{tabular}
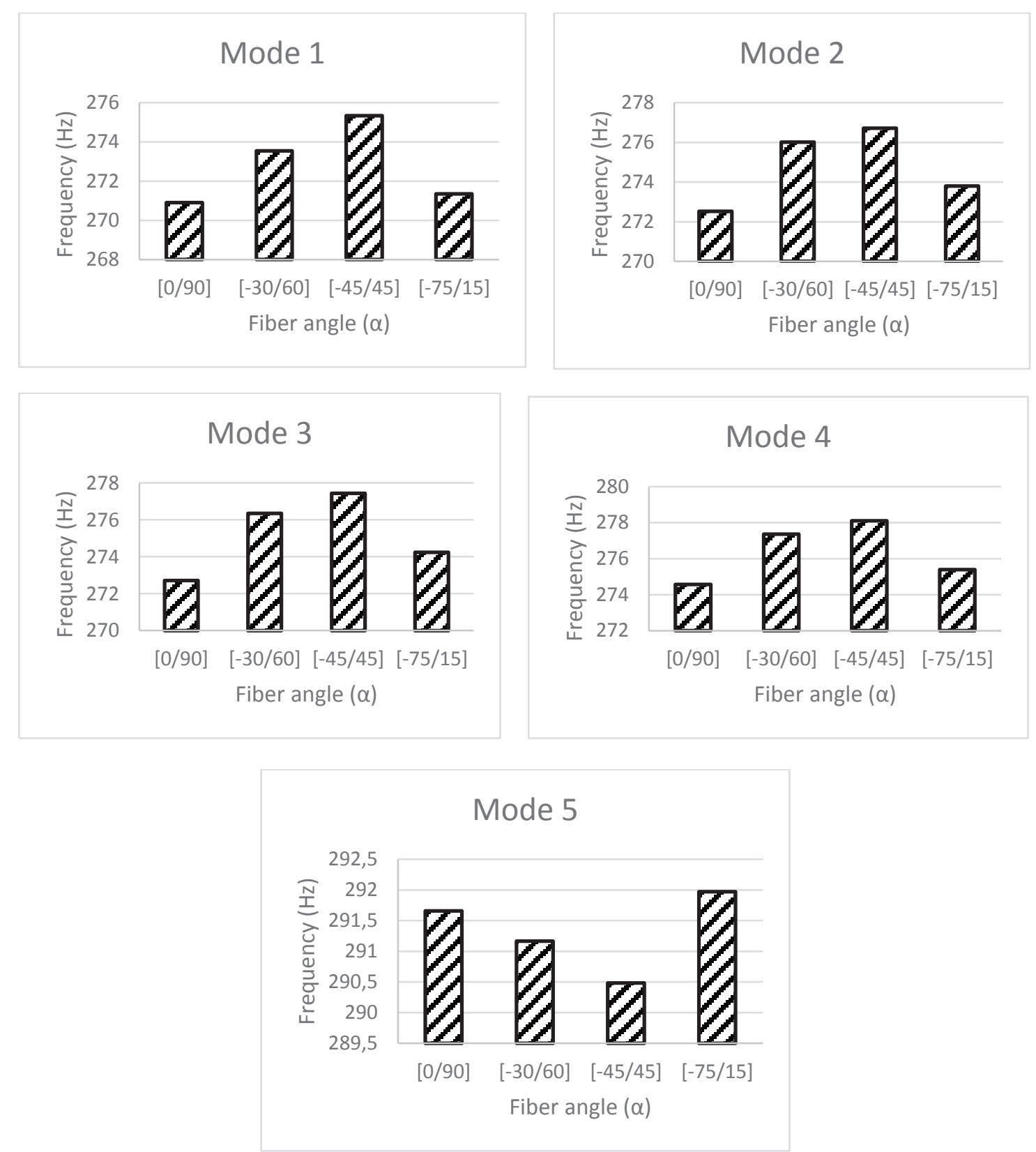

Figure 5. Natural frequency variations of the conical shell structure at different fiber orientation angles and C-C boundary condition 
Table 5. Mode shapes for C-C boundary condition

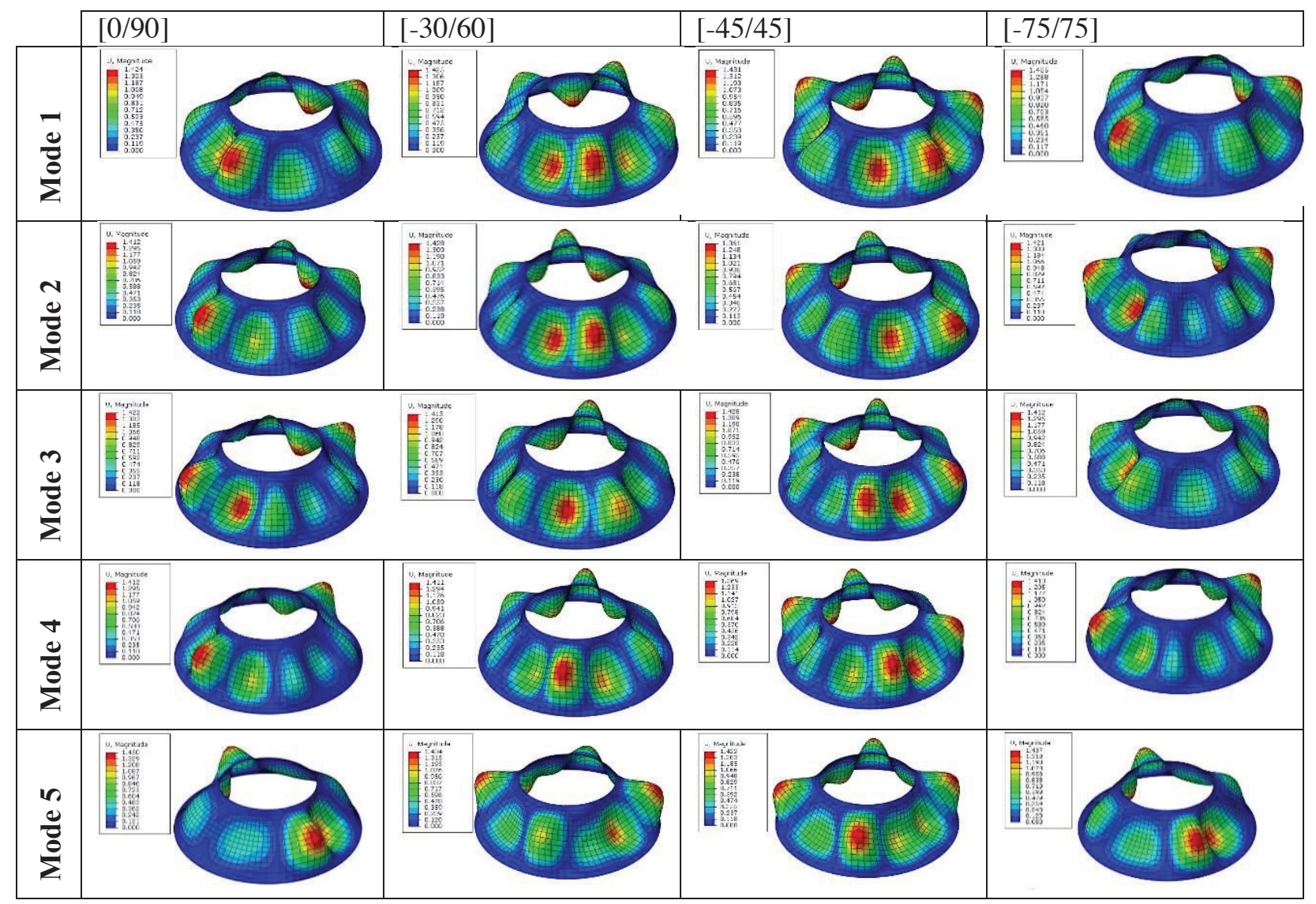

\section{S-S Boundary condition}

Table 6 presents the vibration mode frequencies of the conical shell structure according to fiber orientation angle under the S-S boundary condition, and their fiber orientation angle effects on natural frequency values have been comparatively shown in Figure 6. It is concluded from Table 6 and Figure 6 that optimum frequencies were recorded with stacking sequences of [-45/45] for mode 1,3 , and 4, [-30/60] for mode 2 , and [0/90] for mode 1 . These results imply that deformation and natural frequencies change according to fiber orientations and boundary conditions. When mode shapes of the overall conical shell structure were compared as presented in Table 7, deformation of the shell structure was significantly affected from the boundary condition, but it was not significantly influenced by the fiber orientation effects, and this could be attributed the geometric properties of the shell structure. It is also important that fiber orientations shift the location of maximum deformations, implying that location of the failure during the resonant frequency will be changed when fiber orientation angle changes.

Table 6. Results for S-S boundary condition

\begin{tabular}{ccccc}
\hline \multicolumn{5}{c}{ Fiber angle } \\
\hline Mode & {$[0 / 90]$} & {$[-30 / 60]$} & {$[-45 / 45]$} & {$[-75 / 15]$} \\
\hline $\mathbf{1}$ & 242.1821 & 245.1031 & 247.367 & 242.7891 \\
\hline $\mathbf{2}$ & 244.4475 & 247.7189 & 247.4796 & 245.9294 \\
\hline $\mathbf{3}$ & 245.4333 & 248.6701 & 250.0816 & 246.4957 \\
\hline $\mathbf{4}$ & 247.4257 & 249.8888 & 250.4107 & 248.1991 \\
\hline $\mathbf{5}$ & 265.2808 & 263.9757 & 263.5093 & 265.0611 \\
\hline
\end{tabular}



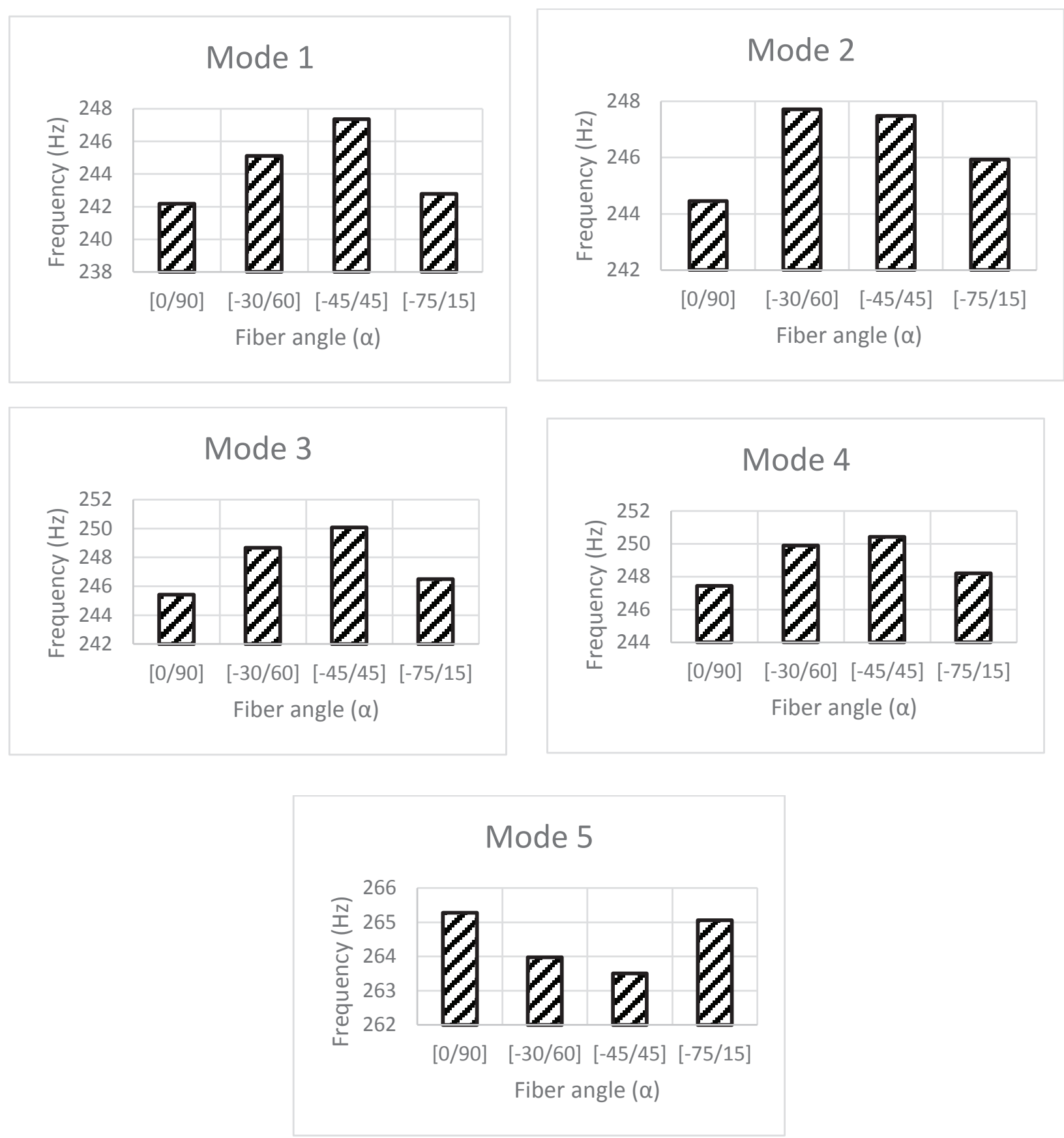

Figure 6. Natural frequency variations of the conical shell structure at different fiber orientation angles and S-S boundary condition

Effects of some geometrical and material parameters on the natural frequencies of composite shells were discussed by Xiang et al. (2014), and their results have shown similar trend in terms of natural frequency compared with this study when increasing mode number associated with fiber orientation angles. In addition, Viswanathan et al. (2015) showed significant enhancement of the natural frequency by end conditions of the conical composite shells, while their fundamental frequencies were little effected by fiber orientation angles indicating similar results in the current study. 
Table 7. Mode shapes for S-S boundary condition

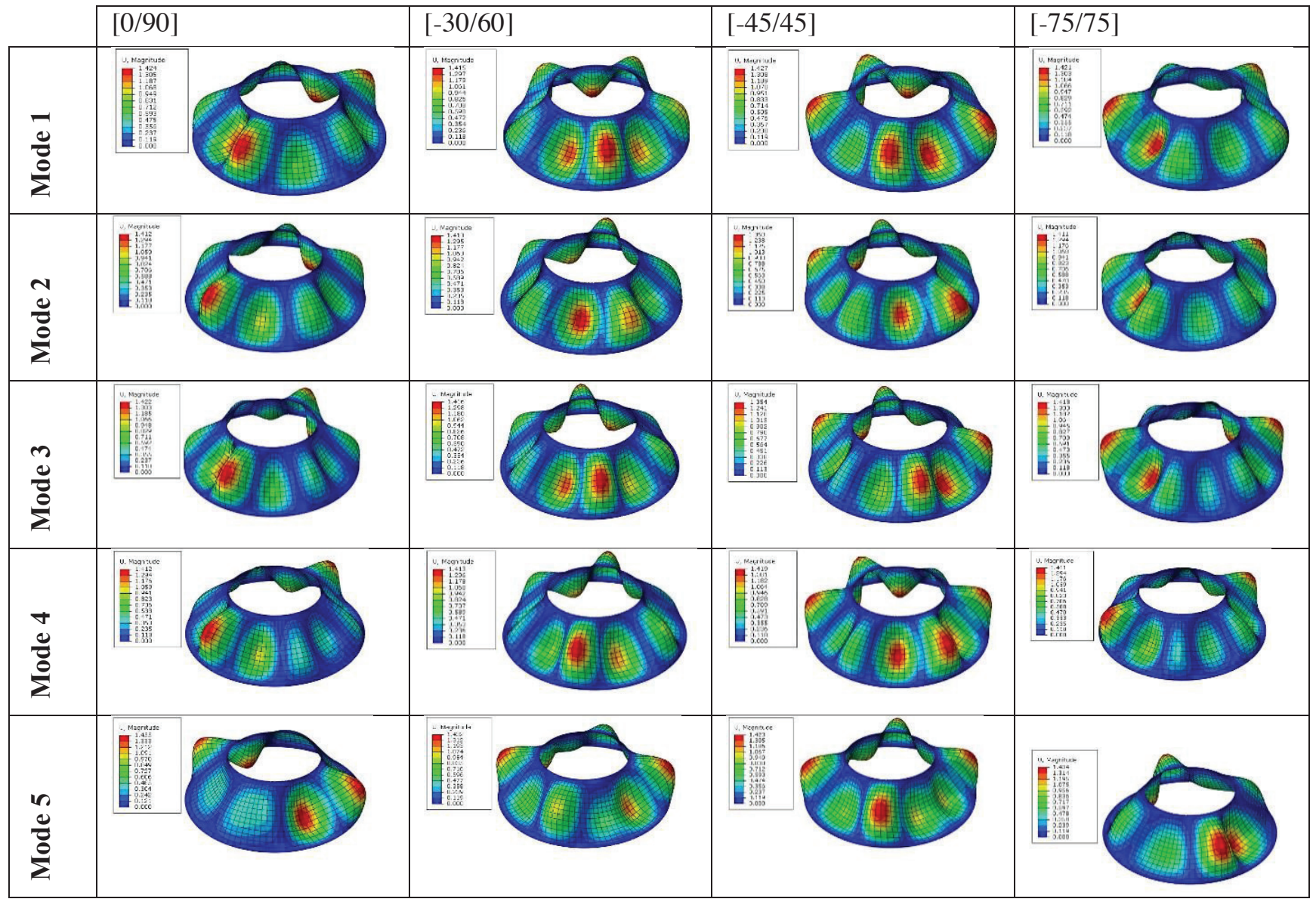

\section{CONCLUSION}

In this study, a numerical investigation has been performed to study the effects of fiber orientation angle and boundary conditions on truncated conical hollow shells made of carbon/epoxy composites. Following conclusions can be drawn from this study:

Mode shapes and maximum deformations of the conical composite shells were effected by fiber orientation angle while increasing mode number from 1 to 5 ,

For C-F boundary condition, natural frequencies were not significantly affected by fiber orientation angle, only resulting in $0.04 \%$ enhancement at fiber angle of [-75/15], and $0.21 \%$ decreasing at fiber angle of $[-45 / 45]$

Natural frequency of the conical composite shell increases as increasing edge constraint of the shell structure from boundary conditions of C-F to CC.

Finally, high deformations as a result of increasing mode number cause the local stress concentrations leading to catastrophic failures in the conical system, and optimum working frequency of the conical composite shell can be arranged for requirement of engineering applications by changing frequency and constraint to meet safety of the system. 


\section{REFERENCES}

Abaqus/CAE User's Guide, 2011. Dassault Systèmes Simulia Corp., Providence, RI, USA,

Akbari, M., Kiani, Y., Aghdam, M.M. and Eslami, M.R, 2014. Free vibration of FGML évy conical panels, Compos. Struct., 116:732-46.

Chang CH, 1978. Membrane vibrations of conical shells. Journal of Sound and Vibration, 60:335-343.

Civalek Ö, 2013. Vibration analysis of laminated composite conical shells by the method of discrete singular convolution based on the shear deformation theory. Compos PartB: Eng., 45:10011009.

Dey S, Karmakar A, 2012. Natural frequencies of delaminated composite rotating conical shells - A finite element approach, Finite Elements in Analysis and Design 56:41-51.

Erkli€ A, Bulut M, Yeter E, 2014. The effect of hybridization and boundary conditions on damping and free vibration of composite plates, Science and Engineering of Composite Materials, 22(5):565-571.

Fares ME, Youssif YG, Alamir AE, 2004. Design and control optimization of composite laminated truncated conical shells for minimum dynamic response including transverse shear deformation, Composite Structures, 64:139-150.

Feng-Ming Li, Kikuo K, Wen-Hu H, 2009. The calculations of natural frequencies and forced vibration responses of conical shell using the Rayleigh-Ritz method, Mechanics Research Communications, 36:595-602.

Goldberg EJ, Bogdanoff JL, Marcus L, 1960. On the calculation of the axisymmetric modes and frequencies of conical shells. J. Acoust. Soc. Amer., 32:738-42.

Goldberg JE, Bogdanoff JL, Marcus L, 1960. On the calculation of the axisymmetric modes and frequencies of conical shells. The Journal of the Acoustical Society of America, 32, 738-742.

Guoyong J, Xianglong M, Shuangxia S, Tiangui Y, Zhigang L, 2014. A modified Fourier series solution for vibration analysis of truncated conical shells with general boundary conditions, Applied Acoustics, 85:82-96.

$\mathrm{Hu}$ HT, Chen PJ, 2015. Maximization of fundamental frequencies of axially compressed laminated truncated conical shells against fiber orientation, Thin-Walled Structures, 97:54-170.
Irie T, Yamada G, Kaneko Y, 1984. Natural frequencies of truncated conical shells, Journal of Sound and Vibration, 92:447-53.

Irie T, Yamada, G, Kaneko Y, 1982. Free vibration of a conical shell with variable thickness, Journal of Sound and Vibration, 82:83-94.

Khatri KN, Asnani NT, 1995. Vibration and damping analysis of multilayered conical shells, Composite Structures, 33:143157.

Lam KY, Li H, 1999. Influence of boundary conditions on the frequency characteristics of a rotating truncated circular conical shell, Journal of Sound and Vibration, 223:171-195.

Lam KY, Li H, 1999. Influence of boundary conditions on the frequency characteristics of a rotating truncated circular conical shell. Journal of Sound and Vibration, 223:171-195.

$\mathrm{Li} \mathrm{H}, 2000$. Frequency analysis of rotating truncated circular orthotropic conical shells with different boundary conditions, Composites Science and Technology, 60:2945-2955.

Liew KM, Ng TY, Zhao X, 2005. Free vibration analysis of conical shells via the element-free kp-Ritz method, Journal of Sound and Vibration, 281:627-645.

Liew KM, Ng TY, Zhao X, 2005. Free vibration analysis of conical shells via the element-free kp-Ritz method. Journal of Sound and Vibration, 281:627-645

Malekzadeh P, Daraie M, 2014. Dynamic analysis of functionally gradedt runcated conical shells subjected to asymmetric moving loads, Thin-Walled Structures, 84:1-13.

Qin Z, Chu F, Zu J, 2017. Free vibrations of cylindrical shells with arbitrary boundary conditions: A comparison study, International Journal of Mechanical Sciences 133:91-99.

Sivadas KR, Ganesan N, 1992. Vibration analysis of thick composite clamped conical shells of varying thickness, Journal of Sound and Vibration, 152: 27-37.

Viswanathan KK, Saira J, Kandasamy P, Aziz ZA, Izliana AB, 2015. Free vibration of anti-symmetric angle-ply laminated conical shells. Composite Structures, 122:488-495.

Xiang X, Guoyong J., Wanyou L., Zhigang L, 2014. A numerical solution for vibration analysis of composite laminated conical, cylindrical shell and annular plate structures. Composite Structures, 111:20-30 